\title{
A Multimodal Discourse Analysis of Political Speeches: The Case of Donald Trump's 2016 Election Speeches
}

\author{
Mohamed Elsanhoury, Abeer M. Refky M. Seddek, Névine M. Sarwat, Riham. E. A. \\ Debian \\ mohamed.elsanhoury2121@gmail.com,dr.abeer.refky@aast.edu,nevine.sarwat@alexu.edu.eg, \\ riham.debian@alexu.edu.eg \\ College of Language and Communication /Arab Academy for Science, Technology and \\ Maritime Transport; Institute of Applied Linguistics and Translation /Alexandria \\ University, EGYPT
}

This paper investigates the different verbal and non-verbal meaning making resources manifested in the speeches of Akron, Ohio and Phoenix, Arizona delivered by Donald Trump during his presidential campaign in 2016. The way verbal and non-verbal resources combine or interact intersemiotically unravels how Donald Trump attempts to affect his audience and reveal his populist leadership. For that end, the researcher carried out an analysis that is divided into two sections. Section one is devoted to a 'themes' analysis to isolate the overarching themes and illuminate the major topics addressed by President Donald Trump to seek his audience's support. Section two follows SF-MDA which relies on Halliday's systemic functional linguistics (Halliday, 1978, 1994; Halliday \& Matthiessen, 2004/2014) for the analysis of verbal meaning- making resources and Kress and Van Leeuwen's visual grammar (1996/2006) for the analysis of non-verbal resources. The analysis reveals that both verbal and non-verbal meaning-making resources, in terms of representational, interactive and compositional meanings, work intersemiotically to deliver a full account of meaning and unravel Donald Trump's populist leadership.

Keywords: multimodal discourse analysis; political speeches; populism; systemic functional linguistics, visual grammar

\section{information}

\author{
Received: \\ 29 January \\ 2020 \\ Revised: \\ 1 May 2020 \\ Accepted: \\ 23 May 2020
}

DOI: 10.24071/joll.v20i2.2390

Available at https://e-journal.usd.ac.id/index.php/JOLL/index

This work is licensed under a Creative Commons Attribute-ShareAlike 4.0 International License

\section{Introduction}

Due to the significant development of multimedia and technology, the way human beings communicate has dramatically changed. Nowadays, people are increasingly exposed to texts that have elaborate visuals, complex layout elements, unusual narrative structures and unique formats (Kress, 2003). In this respect, communication takes place in a variety of modes in which language is an important part. Using these modes in public communication has clearly depicted that meaning is understood not only through 
verbal modes of communication but also through the integration of a wide range of many semiotic resources including verbal and non-verbal ones. The point is that language is almost a part of a bigger whole, namely a text that is made with a number of different modes. Accordingly, communication has become multimodal across various contexts as people who produce texts tend to use many semiotic modes for the production of meaning, resulting in the study of Multimodal Discourse Analysis (MDA).

Jewitt, Bezemer and O'Halloran (2016) define Multimodal Discourse Analysis (MDA) as a field of discourse which deals with the grammar of semiotic resources, with the aim of understanding semiotic resources' functions and the meaning that convoyed when semiotic choices interact or combine over space and time in multimodal phenomena. Political speeches are, thus, considered multimodal in nature. They are the means through which presidential candidates and presidents present themselves to the public and convey meaning in different modes. Bonsignori and Camiciottoli (2017) point out the multimodal nature of political speeches and illustrate the idea that video recorded political speeches provide a wide set of elements that allow analysts to gain a complete understanding of the whole product by adopting a multimodal approach. This creates the need for further research to investigate the way verbal and non-verbal resources are manifested in President Donald Trump's preliminary election speeches.

For scholars working in the field of media and representation, multimodality is a new and intriguing area of research attraction. In the quest of precise analysis of meaningmaking resources, a growing number of studies turn their focus to investigate both language and other semiotic resources through which meaning is constructed. The understanding of meaning in today's world requires the analysis of language as well as the study of other meaning-making resources. This complementarity between all meaningmaking resources helps in delivering a full account of meaning.
A multi-disciplinary review of political speeches in popular discourse and multimodal studies in the literature to date highlights major research gaps that call for investigation. Research work related to the study of multimodal discourse analysis of political speeches is scarce, particularly research that investigates populist leadership of presidential candidates in relation with discourse analysis. On a related note, no studies to date conduct a multimodal analysis of political speeches with respect to verbal and non-verbal meaning-making resources. That is, a multimodal account does not prioritize one semiotic resource over another; rather, every semiotic resource is a meaning momentum or potential.

The 2016 presidential elections in the United States were one of the most important, confrontational and divisive campaigns not only for the history of the United States, but also for the whole world for the enormous power and authority given for this presidency. The result of this election on the $9^{\text {th }}$ of November brought a surprise for the international community. This surprise was the triumph of Donald Trump, the current president of the United States.

Donald Trump is the presidential candidate who has shown his disagreement about the current American's policy and claims that the country needs a proper leadership in order to become great again as it was in the past. He concludes that America is not "great" anymore and not being treated with the respect and dignity a great country deserves. In this respect, he criticizes the current American policy of prioritizing the foreign nations' interests over the American interests and that is how most of the previous presidential administrations have behaved. According to Donald Trump, making "America great again" should have always been one of the ultimate aims of policy makers. It is all about having America the undisputed 'NUMBER ONE' and being treated with the respect it deserves.

With regard to systemic functional multimodal discourse analysis, most scholars barely opt for multimodal inter-disciplinarily, 
thus they are subjective in their interpretation of findings by virtue of their respective field of inquiry. Integrated approaches that are likely to yield more reliable results and insights for the analysis of political speeches are scarce in multimodal studies. Political speeches as a part of human communication are multimodal, for the multiple meaning-making resources they contain. For that end, the researcher adopts MDA which relies on Halliday's Systemic Functional Linguistics (1978) for the analysis of verbal meaning- making resources. Incorporating verbal and non-verbal meaningmaking resources is believed to depict how multimodal ensemble of meaning-making resources presented in the speeches under study.

Most literature on political speeches in general and Donald Trump in particular has been dedicated to traditional discourse analysis, which focuses either on written or spoken language. (e.g. Chen, 2018; Eilola, 2016; Godfrey, 2017; Kleijin, 2017; Liu, 2017; Savoy, 2 017; Zhang, 2017). others studies investigate Donald Trump's populism (e.g. Cullen, 2017; Demata, 2017). The majority of research tends to focus on either verbal or non-verbal resources, while ignoring the way these other communicational modes interact intersemiotically in the meaning-making process (e.g. Aswad, 2018; Boyanska, 2018; Lingling \& Ping, 2017). Exploring previous studies also addresses a research gap in the political discourse of political speeches and points out that the majority of research in the field of MDA has tended to concentrate either on verbal or non-verbal meaning resources, while ignoring or underestimating the complementarity between these meaningmaking resources.

Poggi, D'Errico, Vincze and Vinciarelli (2013) point out that political speeches are multimodal in nature; therefore, they represent a powerful application of MDA due to the various modes of communication included within the speeches. The meaningmaking process in Donald Trump's speeches involves selecting and combing between different modes to convey meaning. The way these modes interact or combine intersemiotically between each other helps Donald Trump as a presidential candidate to present himself to the American public and deliver his agenda. For that end, this paper employs Kress and Van Leeuwen's The Grammar of Visual Design (1996-2006) to analyse and decode the various verbal and non-verbal communicational modes.

MDA is an approach to discourse which expands the study of language as well as other meaning-making resources, such as gestures, images, sound, symbolism and action. MDA is , therefore, concerned with how meaningmaking is realized through the multiplicity of communicational modes. In this respect, MDA always draws on the combination of modes, all of which contribute to meaning. MDA not only describes the full account of meaning - making resources, but also develops means that explain how these resources are combined to produce meaning (O'Halloran, 2013).

The theory of SF-MDA which first introduced by Michael O'Toole's (2011) 'The language of displayed art' and Kress and van Leeuwen's (1996) Reading Images: The Grammar of Visual Design, becomes a proliferating field of research. Following O’Toole's (1994) and Kress and Van Leeuwen's (1996-2006), interest in the use of SF theory for MDA has noticeably risen.

Systemic functional to multimodal discourse analysis goes beyond systemic functional approaches which were largely theorized for modeling discourse and its grammatical systems in language (O'Halloran, 2008). This approach, SFL, has been extended to the analysis of images (Kress \& Van Leeuwen, 2001), art and architecture (O'Toole, 2011), music (Van Leeuwen, 1999) and mathematical images and symbolism (O'Halloran, 2008) in artefacts such as websites and infographics (Jewitt et al., 2016), and films (Bateman, 2014; Bateman \& Schmidt, 2012). The main purpose for this approach is to shed light on the way people use verbal and non-verbal meaning resources in communication (Van Leeuwen, 2005).

With respect to the aforementioned account, it is evident that several multimodal studies are geared toward a multitude of genres. Additionally, most scholars in the field of SF-MDA do not opt for multi-disciplinary 
and are generally biased by their respective specialization and hence are subjective in their interpretation of findings. Moreover, the scarcity of incorporating digital software technology in SF-MDA, particularly with the genre of political speeches under study, is the driving force for its integration. The current research offers an innovative approach of the intersemiosis between verbal and non-verbal meaning making resources manifested in the selected speeches.

\section{Methodology}

The dataset for the study comprises two preliminary election speeches delivered by President Donald Trump during his presidential campaign in 2016. The two speeches were delivered in August 2016 which represents a peaking point in 2016 presidential elections. The first speech was delivered in Phoenix, Arizona on August 31, 2016 and the second speech was delivered in Akron, Ohio on August 23, 2016. Both speeches are retrieved from CNN news channel on www.youtube.com with an average length of 50 minutes for each speech.

Donald Trump's speeches in Ohio and Phoenix cover a number of topics, ranging from foreign policy, opponent corruption, the issue of illegal immigrants, national security, trade and economy. They also mark the first public encounter of Donald trump's beliefs. In the selected speeches, immigrants, opponents and the current establishment are shown to be against America and portrayed negatively by Donald Trump.

\section{Practical Framework}

In the light of SF-MDA, the current study relies on Halliday's SFL (Halliday, 1978, 1994; Halliday \& Matthiessen, 2004/2014) for the analysis of verbal meaning-making resources and Kress and Van Leeuwen's visual grammar $(1996 / 2006)$ for the analysis of non-verbal resources. Kress and Van Leeuwen follows Halliday's theory of metafunctions (1994; 2004; Halliday \& Matthiessen 2004), which proposes that language is realized through three metafunctions simultaneously, namely ideational, interpersonal and textual. The same metafunctions have been extended to visual social semiotic resources by Kress and van Leeuwen (1996-2006) and renamed as representational, interactive and compositional for a full account of meaning.

Halliday's analytical tools are adopted and tabulated to examine the systems of 'transitivity', 'mood' and 'thematic structure', respectively. This is to identify the verbal manifestations presented in the speeches under study. Detailed description, interpretation and explanation are then provided in the light of frequency tables with special reference to the review of related literature to pinpoint salient pattern across the selected speeches.

While, on the other hand, Kress and Van Leeuwen's visual grammar (1996-2006) is adopted by the researcher to identify nonverbal resources by means of 'representational', 'interactive', 'compositional' meanings; representational meaning is examined in terms of 'action processes'; interactive meaning is examined in terms of 'social distance', 'perspective/point of view', 'modality'; and compositional with respect to 'information value', 'salience', 'framing'.

Kress and Van Leeuwen's theoretical framework (1996-2006) offers several advantages with regard to the analysis of texts from a multimodal perspective. It offers a This comprehensive framework analyses semiotic resources based on Halliday's metafunctional principle (1978) where the internal organization of meaning - making resources is seen to represent their respective functions. SF- MDA is, therefore, an approach that bridges the semantic gap between the low features and their associated strands of meaning to be interpreted in relation to the situational and cultural context of any multimodal text.

\section{Analysis of Verbal and Non-verbal Resources}

Based on Kress and van Leeuwen's the grammar of visual design, "representational", "interactive" and "compositional" meanings are used to point out the non-verbal resources 
manifested in the selected speeches. While, on the other hand, Halliday's "ideational", "interpersonal" and "textual" metafunctions are used to explore the verbal resources by examining the systems of "transitivity", "mood" and "thematic structure". This is detailed in what follows.

\section{Procedure}

In order to conduct the analysis, the two speeches under investigation are uploaded onto the MMVA software and later synchronized with video player, the filmstrip, the sound strip, the time-stamped nodes and the corresponding verbal transcription in the transcription window. Then, System choices in the software's Graphic User Interface (GUI) are modified in accordance with the theoretical framework of Kress and Van Leeuwen's (1996) the grammar of visual design. After that, the selected speeches are analysed means of 'representational', 'interactive' and 'compositional', tracing the major verbal and non-verbal communicational resources associated with dominant themes.

\section{Results and Discussion}

The analysis of the current study is divided into two sections. Section one presents a "theme" analysis to pinpoint the dominant themes that permeate the selected speeches. Section two is devoted to the analysis of verbal and non-verbal resources by means of representational, interactive and compositional meaning using $M M D A$ software, henceforth answering the three sub-questions of the study. This, in effect, unravels the way President Donald Trump affects his audience to seek their support and reveals this populist leadership.

\section{Analysis of Themes}

Analyzing the selected speeches using MMDA software, resulted in finding five dominant themes. Those themes are: 'Immigration', 'Opponent Corruption', 'American National Security', and 'Trade', 'Economy'. It is discernible from the analysis of themes that Donald Trump not only wants to point out the pain and the problems the United States faces, but also evokes fear, anger, frustration and other emotions inside the American public. The analysis also reveals that the strategy of US/THEM is used as a means of distancing and delegitimizing the current administration, the establishment, Donald Trump's opponents, and illegal immigrants. Donald Trump refers to himself and his electorate as "US" to characterize himself as the only suitable candidate to become the President of the United States.

Detailed description, interpretation and explanation of the findings yielded from the theme analysis is carried out as shown in table (1). For every theme discussed, the number of occurrences per speech is presented in the following table for both speeches.

Table 1. Frequency of Dominant Themes Presented in the Speeches of Ohio and Arizona

\begin{tabular}{|c|c|c|c|}
\hline Speech / Issue & Akron, Ohio & Phoenix, Arizona & Total \\
\hline Immigration & $\begin{array}{c}14 \\
(8 \%)\end{array}$ & $162(48.5 \%)$ & $178(35 \%)$ \\
\hline Opponent corruption & $84(48 \%)$ & $64(19 \%)$ & $148(35 \%)$ \\
\hline National Security & 34 (19.5\%) & $84(25 \%)$ & $118(23 \%)$ \\
\hline Economy & $25(14 \%)$ & $18(5.5 \%)$ & $43(8.5)$ \\
\hline Trade & $18(10 \%)$ & $5(1.5 \%)$ & $23(4.5 \%)$ \\
\hline Total & 175 & 333 & 508 \\
\hline
\end{tabular}


It is discernible that the aforementioned themes analysis clearly depicts that president Donald Trump points out the problems that worry the American people in order to get the audience's support and carry our practices that deliver his ideologies and identities. The analysis at this juncture also reveals Donald Trump's willingness to evoke fear, anger and emotions inside the American people by pointing out the pain and the major problems that threaten the American growth. The analysis also pins down Donald Trump's quarrel against the establishment and his opponents in an attempt to characterize himself as the only suitable candidate to become the President of the United States.

It is also noteworthy that the results at this level of analysis show the populist personalization of Donald Trump for many reasons. Firstly, he tends to criticize the establishment and the state of the United States under the leadership of democrats. Being a "populist" is a synonym for those who are "anti-establishment" (Muller, 2017). This is discernible because, in most of the cases, populist's voters and audience are frustrated and suffer from resentment. Secondly, he not only personalizes and poses political conflict against other candidates, such as Barrack Obama and Hillary Clinton, but also insists that they are corrupted and crooked. Finally, when discussing the major problems that face the United States, Donald Trump nominates some examples of victims as a result of the state's corruption to evoke fear, anger and frustration inside the American people.

\section{Representational / Ideational Meaning}

In terms of the representational meaning, analysis is limited to the visual transitivity system in terms of narrative processes.
Narrative processes are constructed visually by means of actions or vectors between the participants. The represented participants in both speeches are engaged in motion and vectors or actions are illustrated in dynamic posture. Narrative processes in the selected speeches mainly include the action processes. For action processes, "the actor is the participant from which the vector emanates, or which itself, in whole or in part, forms the vector" (Kress \& van Leeuwen, 2006). When the represented participants take on the role of actor and goal connected by a vector which emanates from the actor or is represented by the actor itself, the action process is transactional. On the other hand, when there is no goal in an image and vectors are not done or aimed at anyone and leave the viewer to imagine who or what he or she may be communicating with, the action is defined as a non-transactional (Kress and van Leeuwen, 2006).

In Ideationally, analysis at this juncture is limited to the experiential metafunctional line of meaning: transitivity. The transitivity analysis is carried out by the researcher to unravel the different types of processes manifested in the speeches under investigation. The processes can represent what is going on in reality: of doing, happening, feeling, or being. The choice of different processes in the selected speeches reflects Donald Trump's views about certain experiences and behaviors. The transitivity system embodies six processes, namely material, mental, relational, behavioural, verbal, and existential. The term 'process' is used here in an extended sense to cover all phenomena and anything that is expressed by a verb. Remarkably, different processes are noticed in both Akron and Ohio speeches, ranging from 'material', 'relational', 'mental', 'verbal', 'behavioural' and 'existential'.

Table 2. Absolute Values of Process Types Manifested in the Speeches of Ohio and Arizona

\begin{tabular}{|l|c|c|c|}
\hline \multicolumn{1}{|c|}{ Process / Speech } & Akron, Ohio & Phoenix, Arizona & Total \\
\hline Material & $216(42 \%)$ & $419(41.5 \%)$ & $635(41 \%)$ \\
\hline
\end{tabular}




\begin{tabular}{|l|c|c|c|}
\hline Relational & $134(26 \%)$ & $246(24.5 \%)$ & $380(25 \%)$ \\
\hline Mental & $70(13.5 \%)$ & $166(16.5 \%)$ & $236(15.5 \%)$ \\
\hline Verbal & $44(8.5 \%)$ & $\begin{array}{c}92 \\
(6 \%)\end{array}$ & $136(10 \%)$ \\
\hline Behavioral & $33(6.5 \%)$ & $50(5 \%)$ & $83(5.5 \%)$ \\
\hline Existential & $16(3.5 \%)$ & $33(3.5 \%)$ & $49(3 \%)$ \\
\hline Total & $\mathbf{5 1 3}$ & $\mathbf{1 0 0 6}$ & $\mathbf{1 5 1 9}$ \\
\hline
\end{tabular}

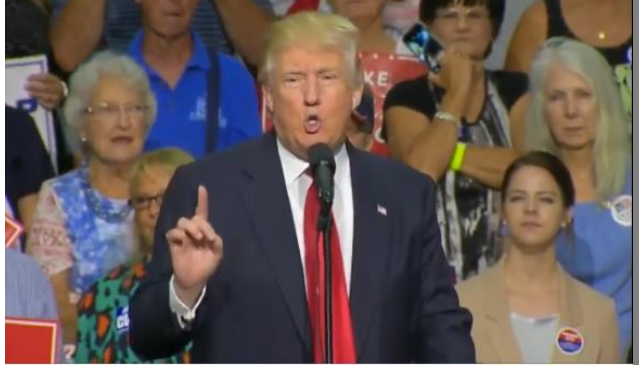

Figure (1)

In terms of representational meaning, figure (1) clearly depicts an action process that is transactional and in nature. Figure (1) has saliently President Donald Trump and his audience as the only represented participants. The represented action process appears to be transactional in nature as the audience are clearly visible. This is evidenced by Donald Trump's hand gestures which take the form of a vector, directing the actions toward the audience. The actor in figure (1) is President Donald Trump, while the goal is his audience.

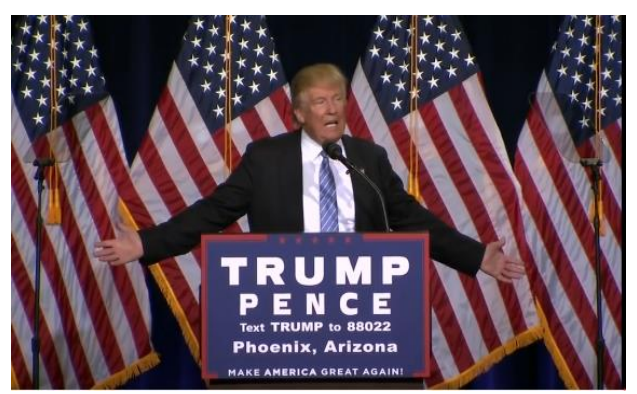

Figure (2)

Figure (2) illustrates action processes that are non-transactional in nature. Donald Trump is the only represented participant. The audience in figure (2) is not clearly visible; therefore, this action process is regarded as non-transactional. This is also indicated by Donald Trump's hand gestures which take the form of a vector, directing his actions towards the audience who are invisible to the viewer. The actor is Donald Trump, while the goal is the invisible audience. It is also noteworthy that the vector or the action is formed by Donald Trump's hand gestures.

\section{Excerpt (1)}

We are going to bring back your jobs that have been taken from your state and every other state in the union. We're going to stop the product dumping, all over the place, dumping, and we're going to stop the unfair foreign subsidies and the currency manipulation, which is a form of cheating. We are going to stop all forms of cheating (Trump, 2016, 0:49)

In terms of ideational meaning, excerpt (1) clearly depicts material processes. These processes are indicated by the verbs "bring", "take" and "stop". Donald Trump uses material processes in order to give promises and signal the actions that will be done if he becomes America's new president by using concrete and directional actions. These material processes are also used to describe the actions the new government will take to improve the current situation. All these concrete, tangible actions make his speech more powerful and convincing and illustrate his determination to change and take actions immediately.

\section{Excerpt (2)}


Only the out of touch media elites think the biggest problems facing America - you know this, this is what they talk about, facing American society today is that there are 11 million illegal immigrants who don't have legal status. And, they also think the biggest thing, and you know this, it's not nuclear, and it's not ISIS, it's not Russia, it's not China, it's global warming

(Trump, 2016, 14:14)

Excerpt (2) represents mental processes of cognition. The mental process of cognition is indicated by the verbs "think" and "know" which occur in the mind. Mental processes of cognition are used to evoke the process of thinking and knowing in order to pin down one of the biggest problems facing America which is the 'global warming'. The senser is "media elites" as the ones who think and the phenomenon is about "the biggest problem facing America" as the thing which is thought.

\section{Interactive/interpersonal Meaning}

On the interactive meaning, the researcher seeks to explore the interpersonal choices presented in the selected speeches to create involvement or detachment between President Donald Trump and his audience and decipher the various ways Donald Trump performs a speech act. What follows is a detailed analysis of 'image act/gaze', 'size of frame/social distance', 'perspective/ point of view', and 'modality'.

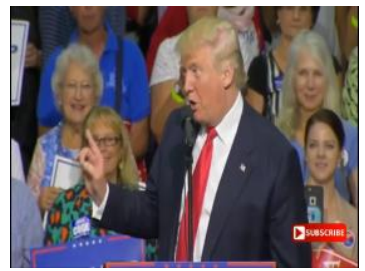

Figure (3)

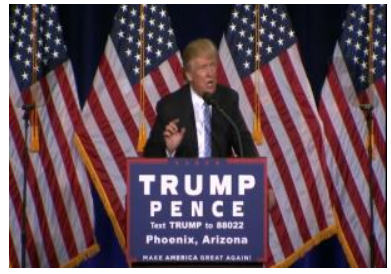

Figure (4)
In term of image act or gaze which can be realized through codes of 'offers' and 'demands', both figures (3) and (4) clearly depict a visual configuration of a demand gaze. This is evidenced by the gaze or the eye contact made by Donald Trump who acts as a represented participant. This visual configuration of a demand gaze not only evokes a response from the audience, but also it engages them in some kind of imaginary relationship. If no gaze is directed at the viewers, there is no imaginary relationship with the viewer (Kress and van Leeuwen, 1996).

In terms of social distance, Donald Trump and his supporters are characteristically positioned in some sort of standing pose and approximately three-quarter of their body appears to be displayed. Most details of their appearance are captured, including their facial expression and body gestures. The size of frame clearly projects an intimate relationship between Donald Trump and his supporters. This is evidenced by the medium shot which implies a sense of more distance and less engagement.

With regard to perspective or point of view, the use of frontal angle dominates all figures. This creates a maximum engagement and involvement whereby the audience is invited to become part of the speech. In terms of power relations level, the use of eye-level vertical angle represents symmetrical power structure and equal power relations between Donald Trump and his audience. If the picture is at the eye level, the relation represents equality between participants (Kress and van Leeuwen, 2006:140).

Another parameter of the interactive meaning is modality which can be established means of visual markers such as contextualization, illumination, representation, and brightness (kress and Van Leeuwen, 2006). In terms of contextualization, figure (1) and figure (3) clearly show contextualization details which are rendered by the background of his supporters. Figure (2) and Figure (4) are also rich with contextualization details. This is evidenced by a series of the United States flags presented in the background of the stage. Regarding illumination, figure (1), figure (2), figure (3) and figure (4) are also rich in terms of illumination as there are no shades or absence of colors. With regard to brightness, all figures demonstrate a high degree of brightness through the various number of colour degrees. The scarcity of black and white colors also shows how high the degree of brightness is. 
Finally, representation is also noticed and evidenced by the clarity of pictorial details presented in the selected figures.

Interpersonally, analysis is limited to the system of mood which can be realized by three different mood systems, namely 'declarative', 'imperative' and 'interrogative'. In the light of the selected speeches, mood depicts the way Donald Trump interacts with his electorate, and is determined by whether a clause is in the declarative, is a command, or is in the form of a question. Declarative clauses act as statements in which Donald Trump provides the audience with information. Besides, the use of imperative clauses in the selected speeches helps to appeal the audience to Donald Trump's directions. Interrogative clauses are used to make the audience concentrate on the content of the selected speeches as shown in table (3).

Table 3. Occurrence of Mood System in the speeches of Ohio and Arizona.

\begin{tabular}{|l|c|c|c|}
\hline \multicolumn{1}{|c|}{ Mood } & Akron, Ohio & Phoenix, Arizona & Total \\
\hline Declarative & $\begin{array}{c}418 \\
(84 \%)\end{array}$ & $\begin{array}{c}653 \\
(85 \%)\end{array}$ & 1071 \\
\hline Imperative & $\begin{array}{c}34 \\
(7 \%)\end{array}$ & $\begin{array}{c}75 \\
(10 \%)\end{array}$ & 109 \\
\hline Interrogative & $\begin{array}{c}45 \\
(85 \%)\end{array}$ & $\mathbf{5 7} \%$ & 82 \\
\hline Total & $\mathbf{4 9 7}$ & $\mathbf{7 6 5}$ & $\mathbf{1 2 6 2}$ \\
\hline
\end{tabular}

\section{Excerpt (3)}

Can you imagine? In a Trump administration all immigration laws will be enforced, will be enforced. As with any law enforcement activity, we will set priorities. But unlike this administration, no one will be immune or exempt from enforcement. And ICE and Border Patrol officers will be allowed to do their jobs the way their jobs are supposed to be done. What do you have to lose? (Trump, 2016, 35:46)

Excerpt (3) depicts declarative and interrogative clauses. President Donald Trump, on one hand, uses declarative clauses to convey certain messages and make a series of promises to make America's future bright again. On the other hand, interrogative clauses are used by Donald Trump in the selected speeches to demand information and get an answer for his questions. The answer will not only make his audience concentrate on the content of the speech, but also give some reasons that qualify him to be the next president. It is noteworthy that the use of rhetorical question or interrogative clause in the above example serve to highlight the inadequacy of Obama and Clinton by their lack of results.

\section{Excerpt (4)}

Clinton has also pledged to add a third executive amnesty. And by the way, folks, she will be a disaster for our country, a disaster in so many other ways.

And don't forget the repeal and replacement of Obamacare. And don't forget building up our depleted military. And don't forget taking care of our vets. Don't forget our vets. They have been forgotten. (Trump, 2016, 34;13)

Excerpt (4) illustrates declarative and imperative clauses. Declarative clauses are used to deliver certain messages and convey information regarding the corruption of his opponent. The use of imperative in this example not only helps to reinforce Donald 
Trump's authority by motivating the audience to act towards particular actions, but also narrow the gap between the audience and Donald Trump. This, in turn, makes the act of advice proposed by Donald Trump a friendly one. Having an act of advice also tones down the authoritarian nature of imperative used, even when realized as commands.

\section{Compositional/Textual Meaning}

According to Kress and van Leeuwen (1996-2006) image composition is realized in terms of three systems or principles, namely information value, salience, and framing.

In terms of information value, the placement of the represented participants in the aforementioned figures take on key information roles. Those represented participants are compositionally organized neither according to the horizontal axis (Given - New) nor in terms of the vertical axis (Ideal Real) but from the centre-margin configuration perspective. The centre-margin layout places Donald Trump in the centre to provide with the nucleus of information on which all the other elements are to some extent subservient.

Another parameter of compositional meaning is salience. Salience creates a hierarchy of elements in the composition and this is achieved by the placement of elements in the foreground or background, their size and contrast in colors and sharpness (Manca, 2017). In figure (1), figure (2), figure (3) and figure (4), Donald Trump and his stage are the most salient and conspicuous items. This is because the size of Donald Trump within the frame, the sharpness of colors, and predominance of the blue, white and red colors which represent the American flag in the background.

Framing represents the third key element of a composition and it play a great role in creating connection or disconnection between the elements of the visual composition. In figure (1), figure (2), figure (3) and figure (4), visual elements are discernible and seem to be connected. This is achieved by the presence of frame lines within the visuals and the brightness of colors dividing the frames. Wellstructured framing between the visual elements plays an important role in the meaning-making process. Verbal and nonverbal resources work in tandem to reiterate how the combination between them helps in the meaning-making process and drive Donald Trump's audience towards particular actions.

\section{Conclusion}

It is discernible that both verbal and nonverbal meaning-making resources, in terms of representational, interactive and compositional meanings, work intersemiotically to deliver a full account of meaning and unravel Donald Trump's 'populist' and 'authoritarian' personalization.

In terms of representational (ideational) meaning, the complementarity of verbal material processes as well as non-verbal narrative action processes is quite revealing and presents Donald Trump as a man of action. This complementarity not only shows Donald Trump's willingness to exert power to influence his audience through actions, but also proves that Donald Trump runs a 'populist' electoral campaign. Populists usually present themselves as strong leaders and they take a step further, crafting an image of men of actions, rather than words without fear to take difficult and quick decisions, even against experts' advice (Kaltwasser \& Mudde, 2017).

In terms of interactive (interpersonal) meaning, both verbal and non-verbal shows an intimate relationship between Donald Trump and his audience who act as the represented participants. On the one hand, the use of imperative clauses and declarative clauses accompanied with 'I', 'We' helps to narrow the gap between the represented participants and make the act of advice by Donald Trump a friendly one. Donald Trump's ultimate aim of this close relation is to define and present what a unified nation can achieve together. Nonverbal resources, on the other hand, create a maximum involvement between the represented participants, evidenced by visual configurations of 'demand gaze', 'medium shot', 'frontal angle', 'eye level vertical angle', 'high level of modality'. It is noteworthy that 
the complementarity between both verbal and non-verbal resources, in terms of interactive meaning, has a great effect on the audience and shows the intimate relationship between Donald Trump as a 'populist' and his audience. Populists always refer to themselves as they are one of the people and for the people (Muller, 2017).

In terms of compositional (textual) meaning, the disposition of verbal and nonverbal resources as well as the emphasis given to the representational and interactive elements that compose meanings achieve a sense of coherence to the whole unit. This, in turn, has a great effect on the audience and helps to provide Donald Trump's audience with all the necessary tools for a full account of meaning. It is also noteworthy that the complementarity between meaning making resources plays an important role in making the audience focused on the content of the speeches.

\section{References}

Aswad, N. G. (2018). Exploring Charismatic Leadership: A Comparative Analysis of the Rhetoric of Hillary Clinton and Donald Trump in the 2016 Presidential Election. Presidential Studies Quarterly, 49(1), 56-74. doi: 10.1111/ psq.12490.

Bateman, J. (2014). Multimodality and genre: a foundation for the systematic analysis of multimodal documents. London: Palgrave Macmillan.

Bonsignori, V., \& Camiciottoli, B. C. (2017). Multimodality across Communicative Settings, Discourse Domains and Genres. Newcastle-upon-Tyne: Cambridge Scholars Publishing.

Boyanska, I.N. (2018). The Appeal of Donald Trump's Political Rhetoric: A Critical Discourse Analysis (Unpublished BA dissertation). Universitat Autonoma de Barcelona, Barcelona.

Chen, W. (2018). A Critical Discourse Analysis of Donald Trump's Inaugural Speech from the Perspective of Systemic Functional Grammar. Theory and Practice in Language Studies, 8(8), 966.

Cullen, J. (2017). The system is rigged: A discursive analysis of Donald Trump and Bernie Sanders [Master's thesis, London school of Economics and political science]. ProQuest Dissertations Publishing.

Demata, M. (2017). A great and beautiful wall. Journal of Language Aggression and Conflict Public Debates on Immigration, 5(2), 274-294. doi: 10.1075/jlac.5.2.06dem

Godfrey, S. (2017). The of Anti-intellectualism: A Study of the Presidential Rhetoric of Barrack Obama and Donald Trump (Master's thesis) Hofstra University, ProQuest Dissertations Publishing.

Halliday, M. A. K. (1978). Language as a social semiotic: The social interpretation of language and meaning. Baltimore, MD: University Park Press.

HALLIDAY, M. A. K. (1994). An introduction to functional grammar. London: Edward Arnold.

Halliday, M. A. K. (2004). An Introduction to Functional Grammar. London: Hodder Education.

Halliday, M. A. K., \& Matthiessen, C. M. I. M. (2014). An introduction to functional grammar. Milton Park, Abingdon, Oxon: Routledge.

Hyland, K., \& Paltridge, B. (Eds). (2013). Bloomsbury companion to discourse analysis. London: Bloomsbury Academic. 
Jewitt, C., Bezemer, J. J., \& O’Halloran, K. L. (2016). Introducing multimodality. London: Routledge.

Kress, G., \& van Leeuwen, T. (1996). Reading images: The grammar of visual design. New York: Routledge.

Kress, G. \& van Leeuwen, T. (2001). Multimodal Discourse: The Modes and Media of Contemporary Communication. London: Arnold.

Kress, G. (2003). Literacy in the new media age. London: Routledge.

Kress, G., \& Van Leeuwen, T. (2006). Reading Images. The Grammar of Visual Design (2nd ed.). London: Routledge.

Manca, E. (2017). Persuasion in tourism discourse: methodologies and models. Newcastle upon Tyne: Cambridge Scholars Publishing.

Liu, C. (2017). Reviewing the Rhetoric of Donald Trump's Twitter of the 2016 Presidential Election [Master's thesis, Jönköping University]. ProQuest Dissertations Publishing.

$\begin{array}{lll}\text { Müller, J.-W. } & \text { (2017). What is }\end{array}$ populism? London: Penguin Random House.

O’Halloran, K. L. (2008). Mathematical discourse: Language, symbolism and visual images. London : Continuum.

O'Halloran, K. L. (2013). Multimodal Discourse Analysis. In Hyland, K., \& Paltridge, B. (Eds), Bloomsbury Companion to Discourse Analysis (Pp.320-3). London: Bloomsbury Academic.

Hyland, K., \& Paltridge, B. (2013). Bloomsbury companion to discourse analysis. London: Bloomsbury Academic.

O'Toole, L. M. (2011). The language of displayed art. London: Routledge.
Ping, K., \& Lingling, L. (2017). Application of Interpersonal Meaning in Hillary's and Trump's Election Speeches. Advances in Language and Literary Studies, 8(6), 28. doi: 10.7575/aiac.alls. v.8n.6p.28

Poggi, I., DErrico, F., Vincze, L., \& Vinciarelli, A. (2013). Multimodal Communication in Political Speech, Shaping Minds and Social Action. Berlin, Heidelberg: Springer Berlin Heidelberg.

Savoy, J. (2017). Trump's and Clinton's Style and Rhetoric during the 2016 Presidential Election.Journal of Quantitative Linguistics, 25(2),168-189. doi: 10.1080 /09296174.2017. 1349358.

Schmidt, K.-H., M., \& Bateman, J. A. (2012). Multimodal Film Analysis: How Films Mean. London: Routledge.

Trump, D. J. (2016, August 23). Full Speech: Donald Trump Rallies in Akron, Ohio [Video file]. YouTube. https://www.youtube.com/watch?v=aEv P_xQLopI

Trump, D. Jr. (2016, August 31). Full Speech: Donald Trump Phoenix Rally - MUST WATCH Immigration Speech - FNN 8/31/2016 [Video file]. YouTube. https://www.youtube.com/watch?v=UB SuRTM1TGY

Yujie, Z. (2018). Transitivity Analysis of American President Donald Trump's Inaugural Address. International Journal of Literature and Arts, 6(2), 28. doi: 10.11648/j.ijla.20180602.11

Zhang, Y. (2017). Transitivity Analysis of Hillary Clinton's and Donald Trump's First Television Debate. International Journal of Applied Linguistics and English Literature, 6(7), 65. doi: 10.7575/ aiac.ijalel.v.6n.7p.65 